\title{
Expression of a novel factor, short-type PB-cadherin, in Sertoli cells and spermatogenic stem cells of the neonatal rat testis
}

\author{
J Wu, W F Jester Jr, A L Laslett, A Meinhardt ${ }^{\mathbf{1}}$ and J M Orth \\ Department of Anatomy and Cell Biology, Temple University School of Medicine, 3400 North Broad Street, Philadelphia, Pennsylvania 19140, USA \\ ${ }^{1}$ Philipps University of Marburg, Marburg, Germany \\ (Requests for offprints should be addressed to JWu; Email: jwu00004@temple.edu)
}

\begin{abstract}
In the rodent testis, contact-mediated interactions between gonocytes, or neonatal stem cells, and Sertoli cells are critical for development. Previously, we showed that the neural cell adhesion molecule (NCAM) serves as a Sertoli cell-gonocyte attachment factor in neonates. Its expression decreases dramatically by 1 week of age and eventually disappears in vivo, and appears to be downregulated by thyroid hormone (tri-iodothyronine $\left(\mathrm{T}_{3}\right)$ ). In this study, we used a cDNA microarray to screen for additional adhesion factors which might be important in testes of developing rats and detected expression of a novel factor, short-type PB-cadherin (STPB-C). Next, RT-PCR was used to generate cDNA for STPB-C from total RNA isolated from co-cultures, cDNA was cloned into pPCR-Script Amp SK(+) cloning vector, and plasmid DNA was isolated and sequenced to confirm the fidelity of the STPB-C cDNA portion of the plasmid. In situ hybridization analyses of testicular sections indicated that STPB-C expression in neonates is localized in the cytoplasm of many, but not all, gonocytes and in the cytoplasm of most of the surrounding Sertoli cells. Parallel

hybridizations carried out on co-cultures also demonstrated a strong cytoplasmic signal in some gonocytes and in the great majority of the Sertoli cells of the underlying monolayer. With Northern analyses we found that STPB-C is expressed in vivo at high levels between days 1 and 5 , with a subsequent large drop by day 10 and thereafter, suggesting that its expression may be associated with Sertoli or germ cell differentiation. Subsequent analyses of co-cultures exposed under a variety of conditions to $\mathrm{T}_{3}$ suggest that, unlike NCAM, STPB-C is not regulated by this hormone. Next, we studied production of STPB-C protein by using an antiserum recognizing a peptide sequence unique to this factor in Western blotting and in immunolocalization. Signal was detected both intracellularly and at cell surfaces in most Sertoli cells and many gonocytes, although many of the latter cell type were also found to be negative for the protein, suggesting a potential role for STPB-C in survival and further development of some of these germ cells from which all subsequent spermatogenic cells originate.

Journal of Endocrinology (2003) 176, 381-391
\end{abstract}

\section{Introduction}

Fertility in adult male rats is dependent on the production of adequate numbers of normal, mature spermatogenic cells. These critical cells all arise from a parent germ cell type, the gonocyte or neonatal stem cell, which in rats begins its postnatal development just after birth. Maturation of gonocytes in the newborn rat as well as sperm development in adults depends at least in part on proper communication between the germ cells and the somatic cell population, the Sertoli cells. This intercellular communication results in intracellular signaling events (Vleminckx \& Kemler 1999) and no doubt involves maintenance of physical contact between the two cell types. For example, our work (Orth et al. 1988, Orth \& Boehm 1990, Orth \& McGuinness 1991, Orth \& Jester 1995, Li et al. 1998) and that of others (Wright 1993) indicates that both gonocytes from newborns and maturing germ cells from adults require contact with Sertoli cells to survive for any appreciable length of time in vitro. Similar germ cell-Sertoli cell interactions are also important in vivo, as evidenced by data from numerous sources (Griswold 1995, Weinbauer \& Wessels 1999, Orth et al. 2000). Thus, identifying the precise mechanisms involved in these interactions and how they are regulated is a crucial step in exploring critical aspects of testicular development and function.

Recently, new information has become available clarifying the molecular basis for at least some Sertoli cell-germ cell interactions in newborn rats. We demonstrated that a non-cadherin, the neural cell adhesion molecule (NCAM), maintains attachment between neonatal Sertoli and germ cells both in vivo and in vitro (Orth \& Jester 1995, Li et al. 1998). We also found that NCAM is substantially 
down-regulated after postnatal day 5 in vivo and absent from the adult seminiferous epithelium. Thus, it is likely that other adhesion factors are also important in the developing and mature testis since NCAM becomes unavailable as the newborn matures. Interestingly, the adult rat testis also expresses a number of cadherin superfamily members, such as $\mathrm{E}-, \mathrm{N}$ - and $\mathrm{P}$-cadherin, cadherin- $6,-8,-10$ and -11 , and members of the PCDH $\alpha$ family of cadherins (Johnson et al. 2000). The presence of a variety of cadherins suggests that one or more of these factors may also be important for interactions between germ cells and Sertoli cells of developing rats.

In spite of the obvious importance of physical interactions between Sertoli and germ cells, the identity and regulation of factors that support their adhesion remains largely unknown. In our previous work (Laslett et al. 2000), we found the tri-iodothyronine $\left(\mathrm{T}_{3}\right)$-stimulated down-regulation of NCAM is accompanied by detachment of approximately $80 \%$ of gonocytes from co-cultures. However, the remaining 20\% of these cells retain attachment and survive, presumably due to the presence of an alternative adhesion factor. Thus, we undertook the current study to identify new adhesion factors in the neonatal testis which might be responsible for continued attachment and survival of some gonocytes during this period of development.

Initially, we screened well-characterized Sertoli cellgonocyte co-cultures with a cDNA microarray to identify candidate molecules and found a novel and potentially important factor, short-type PB-cadherin (STPB-C), which was hitherto undetected in the testis. We studied its expression both in vivo and in vitro with in situ hybridization and subsequently found with Northern analysis that it is expressed at highest levels in neonates and at substantially diminished levels thereafter. In addition, because of the recognized role of $\mathrm{T}_{3}$ in testicular development (Palmero et al. 1989, 1995, Francavilla et al. 1991, Jannini et al. 1993, Van Haaster et al. 1993, Cook et al. 1994, Simorangkir et al. 1995, 1997), we also asked whether STPB-C expression might be regulated by this hormone. We utilized Northern analysis of co-cultured cells under various conditions of $\mathrm{T}_{3}$ treatment and found no clear-cut relationship between the hormone and STPB-C, at least under the conditions tested. Finally, we used Western analysis and immunolocalization to examine STPB-C protein. We found that STPB-C is produced in vivo in neonatal testes and that its cellular localization suggests that it acts to modify adhesion between Sertoli cells and gonocytes, the stem cells from which all subsequent generations of germ cells arise.

\section{Materials and Methods}

Animals and collection of testis tissue

Male pups were obtained by mating Sprague-Dawley rats (Charles River Breeding Labs, Kingston, RI, USA). All animals were maintained in an environmentally controlled facility with water and lab chow freely available, in accordance with the National Institute of Health guidelines for the care and use of laboratory animals. Testes obtained from adult rats and rat pups (1-5, 10 and 23 days old) were either decapsulated, snap-frozen in liquid nitrogen, and stored at $-70{ }^{\circ} \mathrm{C}$ until extraction of RNA or fixed in freshly prepared $4 \%$ formaldehyde in PBS overnight, followed by rinsing in PBS and routine processing and embedding in paraffin.

\section{Gonocyte-Sertoli cell co-cultures}

Gonocytes and Sertoli cells were isolated and cultured as previously described (Orth \& Boehm 1990, Orth \& Jester 1995). In brief, Sertoli cells and gonocytes were isolated from testes of 2-day-old pups by sequential digestion with collagenase/hyaluronidase and collagenase. A single cell suspension was obtained by incubating cell aggregates in cell dissociation buffer (Life Technologies, Inc., Gaithersburg, MD, USA), and cells were plated on Matrigel (Collaborative Research, Waltham, MA, USA) in either eight-chamber culture slides (Lab-Tek-Nunc, Naperville, IL, USA) or $35 \mathrm{~mm}$ plastic Pertri dishes. Gonocytes and Sertoli cells were cultured in hormoneand serum-free Eagle's D-valine MEM (Sigma, St Louis, MO, USA) supplemented with $1 \mathrm{mM}$ sodium pyruvate, $0 \cdot 1 \mathrm{mM}$ non-essential amino acids, $3 \mathrm{mM}$ sodium lactate, $5 \mu \mathrm{g} / \mathrm{ml}$ transferrin, and $50 \mathrm{ng} / \mathrm{ml}$ retinol in a $5 \% \mathrm{CO}_{2}$ atmosphere at $37^{\circ} \mathrm{C}$ for up to $60 \mathrm{~h}$. Some co-cultures were treated $24 \mathrm{~h}$ after plating with $0,0 \cdot 5,1,5$ or $10 \mathrm{nM}$ $\mathrm{T}_{3}$ (Calbiochem, San Diego, CA, USA), or with $1 \mathrm{nM} \mathrm{T}$ or vehicle for $6,12,24$ or $36 \mathrm{~h}$ in hormone- and serum-free Eagle's D-valine MEM. Each of these incubation regimens was carried out on each of three separate sets of cultures. Results from each set of these incubations were subjected to densitometry and the results analyzed and compared statistically, as described below. For Western or immunofluorescent analysis of STPB-C protein, additional cultures were prepared as above. For immunoblotting, cells were scraped from the dishes, rinsed and frozen, followed by isolation of protein as described below. For immunolocalization, cultures were fixed in freshly prepared $4 \%$ paraformaldehyde in PBS for $10 \mathrm{~min}$, rinsed and processed as described below.

\section{cDNA microarray preparation and hydridization}

After $24 \mathrm{~h}$ of exposure to $10 \mathrm{nM} \mathrm{T}_{3}$ or to vehicle, total RNA was extracted from co-cultures with the Qiagen RNeasy kit according to the manufacturer's instructions (Qiagen, Valencia, CA, USA). The total RNA was then treated with DNase and subsequent lack of contamination of each sample was verified using glyceraldehyde phosphate dehydrogenase (G3PDH) PCR without prior reverse transcription. Only DNA-free total RNA was 

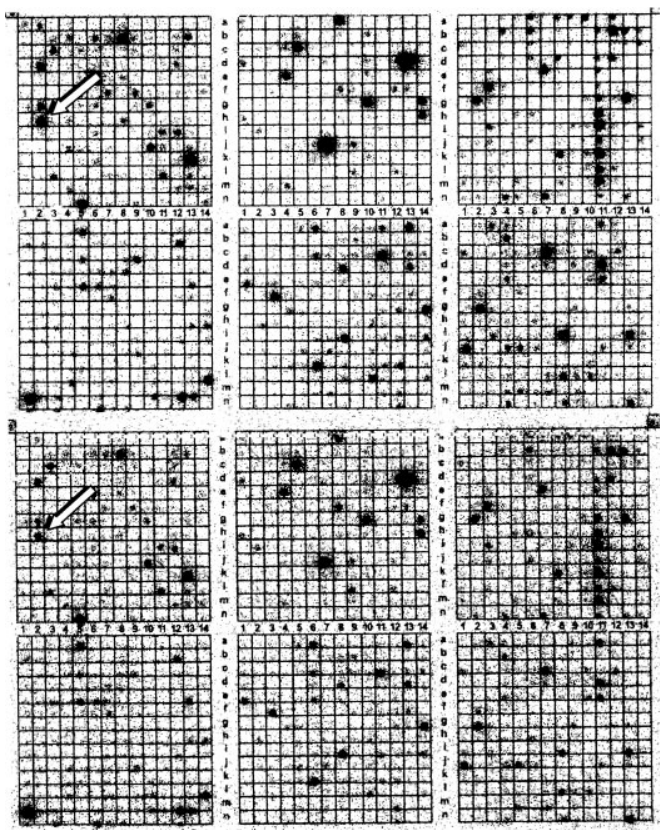

Con

$\mathrm{A} B \mathrm{~B}$

DEF

T3

A B C DEF

Figure $1 \mathrm{~A}$ rat cDNA microarray using RNA isolated from co-cultures with (lower panel) or without (upper panel) prior treatment with $10 \mathrm{nM} \mathrm{T}_{3}$. The white arrows indicate signal corresponding to STPB-C in each panel.

radiolabeled by reverse transcription to generate cDNA probes, which were hybridized to Atlas Rat 1.2 cDNA Expression Arrays (Clontech, Heidelberg, Germany) following the manufacturer's instructions. The membranes were then exposed to PhosphorImage screens overnight and scanned on a Fujifilm FLA-3000 PhosphorImager system (Tilburg, The Netherlands).

\section{Probes}

Total RNA was extracted from co-cultures as described above for cDNA microarray preparation. cDNA was synthesized by reverse transcription of $2 \mu \mathrm{g}$ total RNA using oligo(dT) $)_{12-18}$ primer (Life Technologies) with Superscript II RNase $\mathrm{H}^{-}$reverse transcriptase according to the manufacturer's instructions (Life Technologies). PCR was carried out in a volume of $50 \mu \mathrm{l}$ containing $10 \mu \mathrm{l}$ reverse transcriptase reaction mixture, $1 \times$ PCR buffer (20 mM Tris- $\mathrm{HCl}$ (pH 8.4), $50 \mathrm{mM}$ potassium chloride), $1.5 \mathrm{mM}$ magnesium chloride, $200 \mu \mathrm{M}$ of dNTP mix, $200 \mathrm{nM}$ each of primers (forward primer, 5'-TCAG TGTCCAGCTAGTCTCTC-3'; reverse primer, 5'-AC CCCCCACTTTCTCTTTCC-3'), and 2 U Taq polymerase (Life Technologies). Thirty-two cycles of amplification were performed: denaturation at $94^{\circ} \mathrm{C}$ for $1 \mathrm{~min}$, annealing at $57^{\circ} \mathrm{C}$ for $1 \mathrm{~min}$, followed by extension at $72{ }^{\circ} \mathrm{C}$ for $1.5 \mathrm{~min}$. Amplified DNA (1225 bp) for STPB-C
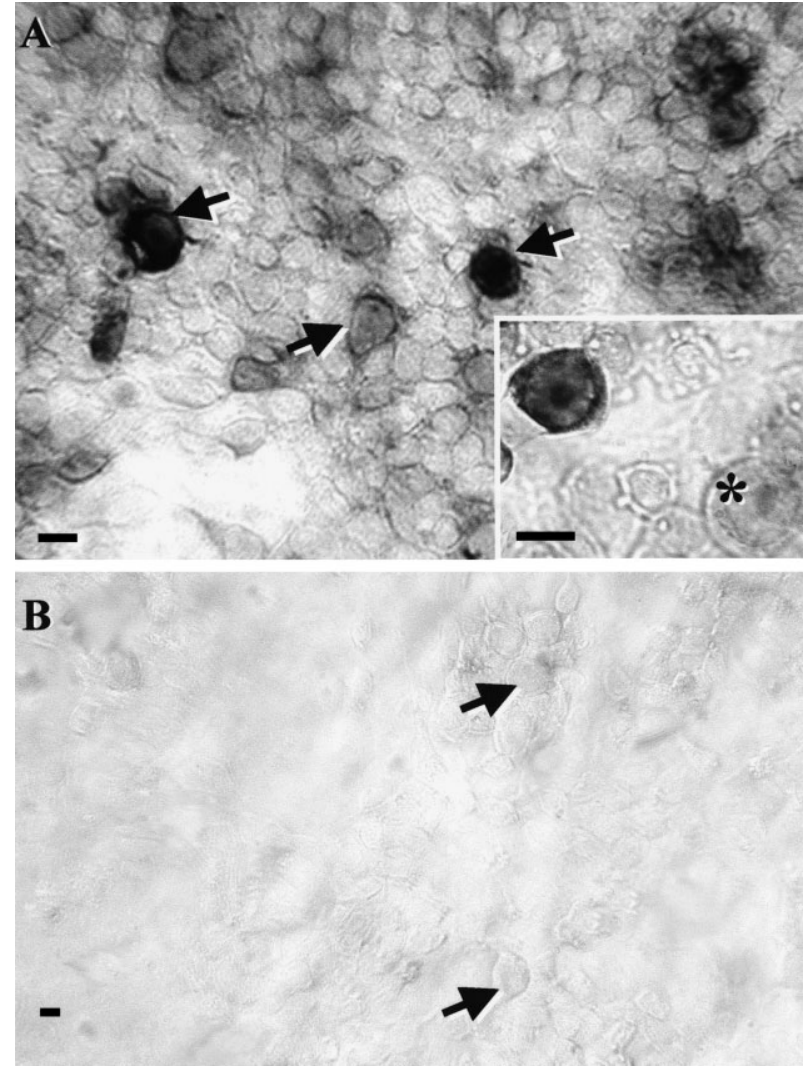

Figure 2 Expression of STPB-C mRNA in co-cultures after $48 \mathrm{~h}$ in vitro. In situ hybridization was carried out with DIG-labeled cRNA antisense (A) or sense (B) probes and viewed with DIC optics. The focal plane of the image is at the level of the gonocytes, recognizable by their large round nuclei and their position, attached to the upper surfaces of the underlying Sertoli cells. In (A) cytoplasmic reaction product indicating the presence of the STPB-C message was prominent in many gonocytes (arrows) in antisense incubations, but other gonocytes lacking product were also common (asterisk in inset). Virtually all of the closely packed cells in the underlying monolayer are Sertoli cells and most of these cells contain a modest amount of signal in their scant cytoplasm. No reaction product was detected in any co-cultures exposed to sense cRNA probes (B; arrows indicate gonocytes). Bar $=10 \mu \mathrm{m}$.

was separated by agarose gel electrophoresis and subcloned into the pPCR-Script Amp SK (+) plasmid vector (Stratagene, La Jolla, CA, USA). Plasmid DNA was cut with the restriction enzyme Kpn1 and Sac1, and analyzed by agarose gel electrophoresis. To confirm the fidelity of the STPB-C cDNA portion of the plasmid, plasmid DNA containing the STPB-C insert was sequenced $(98 \%$ identity).

In situ hybridization

Digoxigenin (DIG)-labeled cRNAs were produced with a DIG RNA labeling kit (Roche Molecular Biochemicals, 

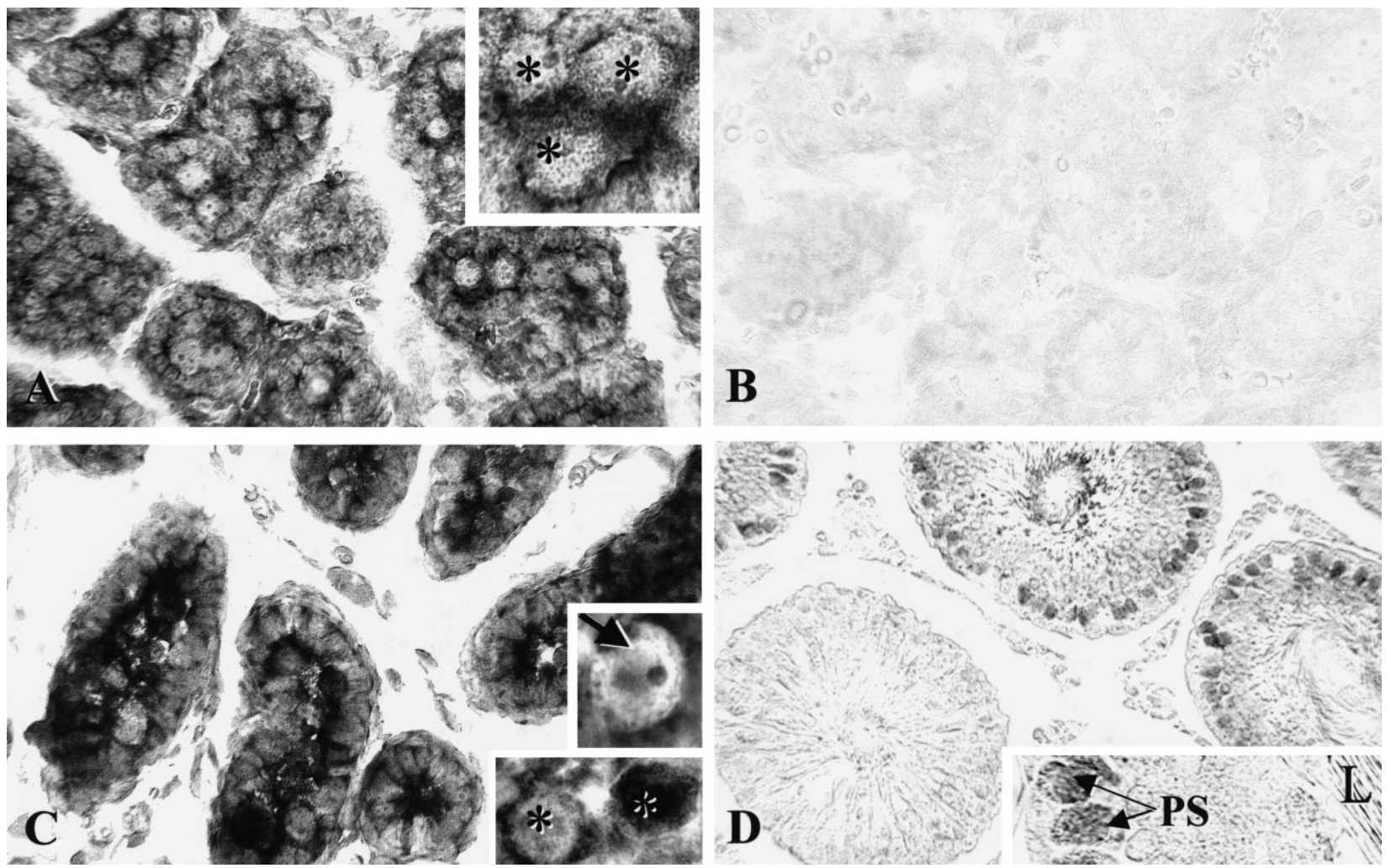

Figure 3 Representative views of in situ hybridizations for STPB-C carried out on tissue sections from 1-day-old (A), 5-day-old (B and C) and adult rats (D). In (A, C and D) sections were incubated with antisense cRNA probes, while in (B) sense probes were used. At all ages prior to day 23, substantial cytoplasmic product was detected in both gonocytes (asterisks in A and C insets) and the surrounding Sertoli cells. However, some gonocytes lacking product (arrow in C inset) were also observed. In older rats (D), product was restricted to the nuclei of apparent primary spermatocytes in most tubules (PS in inset: L, lumen).

Mannheim, Germany) from linearized pPCR-Script Amp SK (+) plasmid containing an STPB-C insert, using T3 and T7 RNA polymerase for sense and antisense probes respectively. Sections of paraffin-embedded tissue were cut (5 $\mu \mathrm{m}$ thick), placed on Super-Frost slides (Fisher Scientific, Irvine, CA, USA), dehydrated and cleared in xylene. Co-cultures and paraffin sections were subjected to in situ hybridization with a minor modification of the method described previously (Orth et al. 1996). Hybridization was at $60{ }^{\circ} \mathrm{C}$ overnight, and washes were in gradually decreasing concentrations of formamide and saline-sodium citrate (SSC), with final stringent washes in $0 \cdot 2 \times \mathrm{SSC}$, all at $60{ }^{\circ} \mathrm{C}$. After completion of posthybridization rinses, sections were preblocked in blocking solution ( $1 \%$ blocking reagent in maleic acid buffer) and then exposed to anti-DIG antibodies conjugated to alkaline phosphatase (Roche; 1:500) at room temperature for $2 \mathrm{~h}$. A nucleic acid detection kit (Roche) was used to visualize hybridized probe in the co-cultures, with reagents supplied in the kit used at recommended concentrations. The color reaction was allowed to proceed for the same length of time for all slides in a single analysis (25-35 min). After rinsing, culture slides were mounted in
PBS:glycerol (1:1). Slides in each group were viewed and photographed with a Leitz Orthoplan 2 microscope (Leitz, Rockleigh, NJ, USA) equipped with differential interference contrast (DIC) optics (Leica, Malvern, PA, USA) and images captured with a digital Optronics Magnafire camera (Optical Apparatus, Ardmore, PA, USA).

\section{Northern blotting}

Total RNA was isolated from testis tissue or co-cultures using the protocol as described above. Samples (10 $\mu \mathrm{g}$ RNA/lane) were run on a $1 \%$ agarose-formaldehyde gel and transferred by capillary action to a nylon membrane (Amersham Pharmacia Biotech, Arlington Heights, IL, USA) in $20 \times$ SSC overnight. After prehybridizing for 30 min in Rapid-Hyb (Amersham Pharmacia Biotech), blots were hybridized with a ${ }^{32} \mathrm{P}-$ labeled cDNA probe produced with the Rediprime kit (Amersham Pharmacia Biotech) according to the manufacturer's instructions. The probe was a Kpn1-Sac1 fragment (1327 bp) containing STPB-C cDNA (1225 bp), obtained from a subclone in a pPCR-Script Amp SK (+) plasmid vector, as described above. After hybridization, blots were 
A
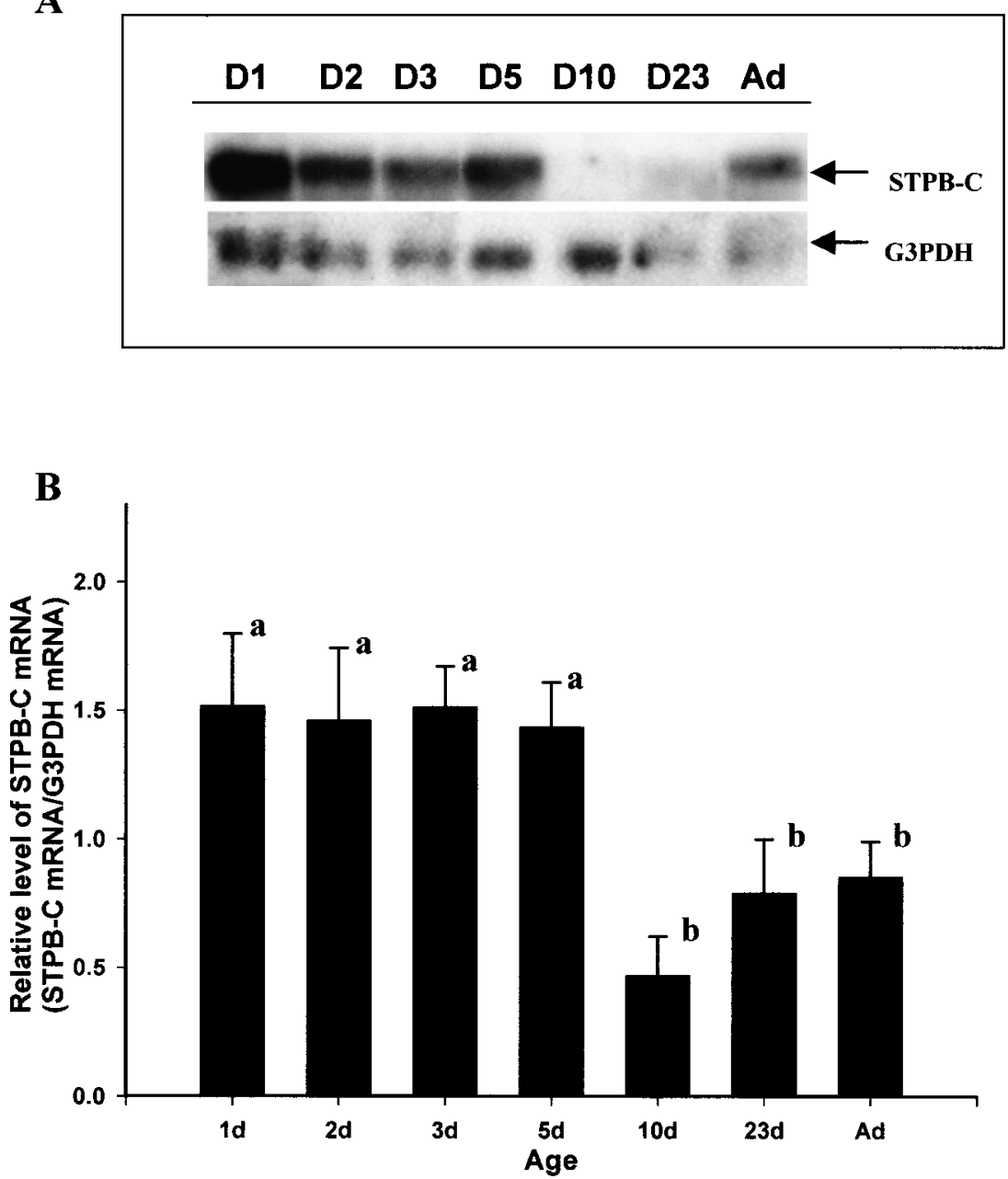

Figure 4 (A) Representative Northern blotting analyses of total RNA from samples obtained from testes on postnatal days 1-5, 10 and 23, or from adult testes (Ad). The expression of G3PDH was used as an internal standard to control for evenness of loading. (B) In each of three replicate analyses, Northern blots were quantified, and the results were expressed as the ratio of STPB-C:G3PDH. The bars represent the means \pm S.E.M. of the data for each age and bars marked with different letters are significantly different from each other $(P<0 \cdot 01)$.

washed in decreasing concentrations of SSC, $0 \cdot 1 \%$ SDS. Autoradiography was performed using Kodak BioMax film (Eastman Kodak, Rochester, NY, USA). Each blot was then stripped using the StripEz DNA kit (Ambion, Austin, TX, USA) according to the manufacturer's directions, and re-probed for G3PDH with an antisense DNA probe produced from a commercially available rat template (Ambion).

\section{Western blotting and immunolocalization}

Antiserum recognizing a peptide sequence unique to STPB-C (GHRGTSNKEDHQCPAS) was raised in rabbits by a commercial source (Resgen, Huntsville, AL,
USA) and utilized for all Western blotting and immunolocalization in this study. Immunoblotting and immunolocalization methods were essentially as previously described (Laslett et al. 2000). In brief, for immunoblotting cells were lysed in buffer containing $50 \mathrm{mM}$ Tris ( $\mathrm{pH} 7 \cdot 4$ ), 1\% Triton X-100, $5 \mathrm{mM}$ EDTA, 1.0 mM phenylmethylsulfonyl fluoride, $10 \mu \mathrm{g} / \mathrm{ml}$ aprotonin and $10 \mu \mathrm{g} / \mathrm{ml}$ leupeptin, followed by incubation at $4{ }^{\circ} \mathrm{C}$ for $60 \mathrm{~min}$. Lysates were then centrifuged at $14000 \mathrm{~g}$ at $4{ }^{\circ} \mathrm{C}$ for $30 \mathrm{~min}$ and supernatants were collected into fresh tubes. Protein concentrations of the supernatants were determined using a bicinchoninic protein assay kit (Pierce, Rockford, IL, USA). Proteins were equally loaded on each gel $(50 \mu \mathrm{g}$ total protein/lane) and separated by electrophoresis on a 
A

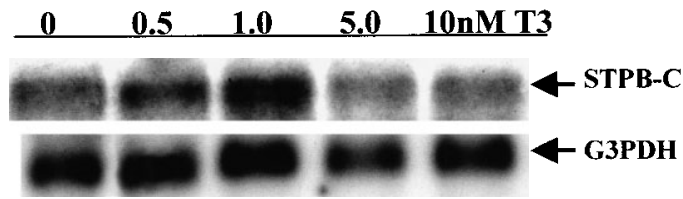

B

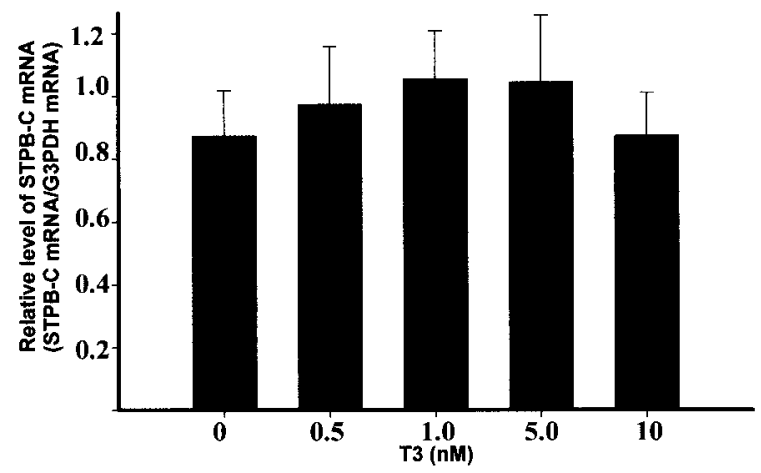

Figure 5 (A) Representative Northern analysis of STPB-C in total RNA samples isolated from co-cultures after incubation with 0 , $0 \cdot 5,1,5$ or $10 \mathrm{nM} \mathrm{T}_{3}$ for $24 \mathrm{~h}$. The expression of G3PDH was used as an internal standard to control for evenness of loading. (B) Northern blots from each of three replicate sets of cultures were quantified by densitometry and the densitometric data were expressed as a ratio of STPB-C:G3PDH for each sample. Means \pm S.E.M. were obtained for each treatment from the three sets of cultures, then plotted and analyzed statistically. No statistically significant differences were seen among the groups.

5\% SDS-polyacrylamide gel, then electrophoretically transferred to a nitrocellulose membrane. After incubation in 5\% dried non-fat milk powder in Tris-buffered saline with $0 \cdot 1 \%$ Tween-20 (TBST) at $4{ }^{\circ} \mathrm{C}$ overnight, membranes were probed for $60 \mathrm{~min}$ at room temperature with STPB-C antiserum (dilution 1:5000), or with preimmune serum (control). After four washes of at least 10 min each in TBST, membranes were incubated with horseradish peroxidase-conjugated goat anti-rabbit $\operatorname{IgG}$ (dilution 1:10 000; Santa Cruz Biotechnology, Inc., Santa Cruz, CA, USA). Antibodies specifically bound to the membrane were visualized by chemiluminescence with a SuperSignal kit (Pierce) applied according to the manufacturer's directions. For immunolocalization of STPB-C in cells, freshly fixed cultures were blocked in 10\% normal goat serum at room temperature for $60 \mathrm{~min}$ and then incubated with primary antiserum diluted 1:100 overnight at $4{ }^{\circ} \mathrm{C}$. Control chambers were incubated either in pre-immune serum or without primary antibody. Following extensive washing in PBS, chambers were incubated in rhodamine-conjugated goat antirabbit secondary antibody (dilution 1:1000; Jackson ImmunoResearch Laboratories Inc., West Grove, PA, USA) for $2 \mathrm{~h}$ at room temperature. After rinsing, slides were mounted in Vectashield containing 4',6-diamidino2-phenylindole (DAPI) (Vector Laboratories, Burlingame, CA, USA) and then viewed with epifluorescence optics on a Leitz Orthoplan microscope and images captured as described above.

\section{Data analysis}

For each Northern analysis, densitometry was used to obtain a numerical value for STPB-C signal and for G3PDH signal, and the final data for each sample were expressed as a ratio of these values. Each analysis was performed in triplicate, and the means obtained from these three values for each treatment group were then analyzed statistically with one-way ANOVA and a StudentNewman-Keuls test.

\section{Results}

\section{cDNA microarray analysis}

To identify potential adhesion factors relevant to germ cell-Sertoli cell interactions, RNA was isolated from Sertoli cell-gonocyte co-cultures. Some of these cultures were treated with $\mathrm{T}_{3}(10 \mathrm{nM}, 24 \mathrm{~h})$ while others received vehicle alone. A cDNA microarray was used to screen for expression of 1176 genes (Atlas Rat 1.2 Array (\#7854-1); Clontech) and signal for several members of the cadherin family of adhesion factors, including STPB-C (grid \#A02 h in Fig. 1), was seen in both sample groups. Based on this observation, we initiated more detailed analyses of STPB-C expression in neonatal testicular cells.

In situ hybridization of $S T P B-C m R N A$ in co-cultures and in sections

To identify and localize STPB-C transcripts in testicular cells in vitro and in vivo, we used DIG-labeled cRNA probes and subsequent immunolocalization with an alkaline phosphatase detection system, as described in Materials and Methods. Co-cultures were fixed after 2 days of culture and then hybridized to either antisense or sense probes. Antisense probes recognizing STPB-C mRNA were predominantly localized to the cytoplasm of many, but not all gonocytes, with a lower amount of product also seen in many Sertoli cells (Fig. 2A). In cultures hybridized to sense cRNA probes, essentially no signal was detected (Fig. 2B). When the same techniques were applied to testicular sections (Fig. 3A and C), a strong signal was seen in the cytoplasm of most but not all gonocytes and also in the cytoplasm of Sertoli cells. In testes from 23-day-old and adult animals, a weaker signal for STPB-C message was observed in some crosssectioned tubules (Fig. 3D). In these areas, product was localized to the nuclei of germ cells whose size and 

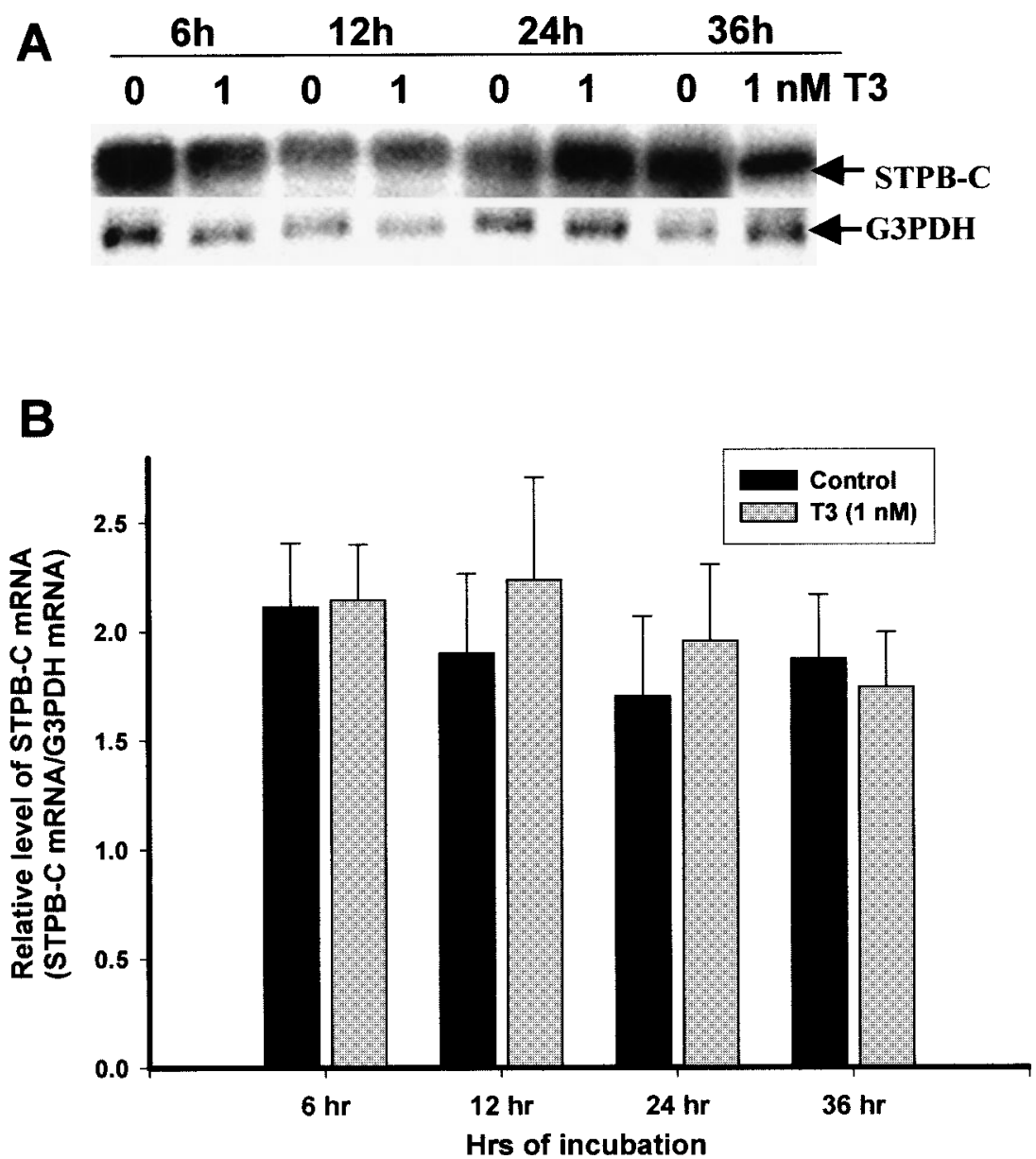

Figure 6 (A) Representative Northern analysis of STPB-C in total RNA samples isolated from co-cultures after incubation with $\mathrm{T}_{3}(1.0 \mathrm{nM})$ or vehicle for $6,12,24$ or $36 \mathrm{~h}$. The expression of G3PDH was used as an internal standard to control for evenness of loading. (B) Northern blots from each of three replicate sets of cultures were quantified by densitometry and the densitometric data were expressed as a ratio of STPB-C:G3PDH. Means \pm S.E.M. were obtained for each time point from the three replicate sets of cultures, then plotted and analyzed statistically. No statistically significant differences were seen among the groups.

position suggest that they are primary spermatocytes. No signal was seen in the cytoplasm of these germ cells. Finally, at all ages essentially no signal was detected in tissue hybridized to sense probes (see Fig. $3 \mathrm{~B}$ for an example).

\section{STPB-C expression during development in vivo}

To assess the developmental pattern of STPB-C expression in rat testes, total mRNA was obtained from testes on days $1,2,3,5,10$ or 23 , or from adults. Northern blotting analysis was applied to these samples (Fig. 4) and the resulting signals from three sets of samples were quantified with densitometry and subjected to statistical analysis. Relative expression of STPB-C (STPB-C mRNA/
G3PDH mRNA) was strong and approximately equivalent on postnatal days $1-5$. However, by day 10 a significantly decreased level of STPB-C expression was detected compared with that on days $1-5 \quad(P<0 \cdot 01)$. Thereafter, on postnatal day 23 and in adults, expression of STPB-C remained relatively low, at levels significantly below those seen on days $1-5(P<0 \cdot 01)$ and not different from that seen on day 10 .

Relationship between $T_{3}$ and expression of STPB-C in co-cultures

The observation of a substantial decrease in STPB-C mRNA after postnatal day 10 raises the possibility that a 
differentiation factor such as $\mathrm{T}_{3}$ may play a role in regulating this adhesion factor (see Discussion). For this reason, we determined whether STPB-C expression is affected by either the level or extent of exposure of co-cultures to $T_{3}$. First, Northern blotting was applied to
RNA isolated from co-cultures exposed to vehicle or to $0 \cdot 5-10 \mathrm{nM} \mathrm{T}_{3}$ for $24 \mathrm{~h}$. When densitometry was used as described in Materials and Methods to quantify and compare signals on Northern blots, we noted a trend suggesting a slight increase in STPB-C signal between

$\mathbf{A}$

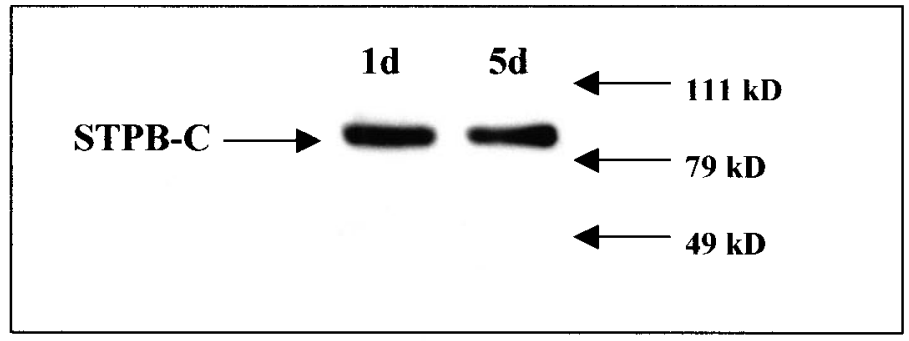

B
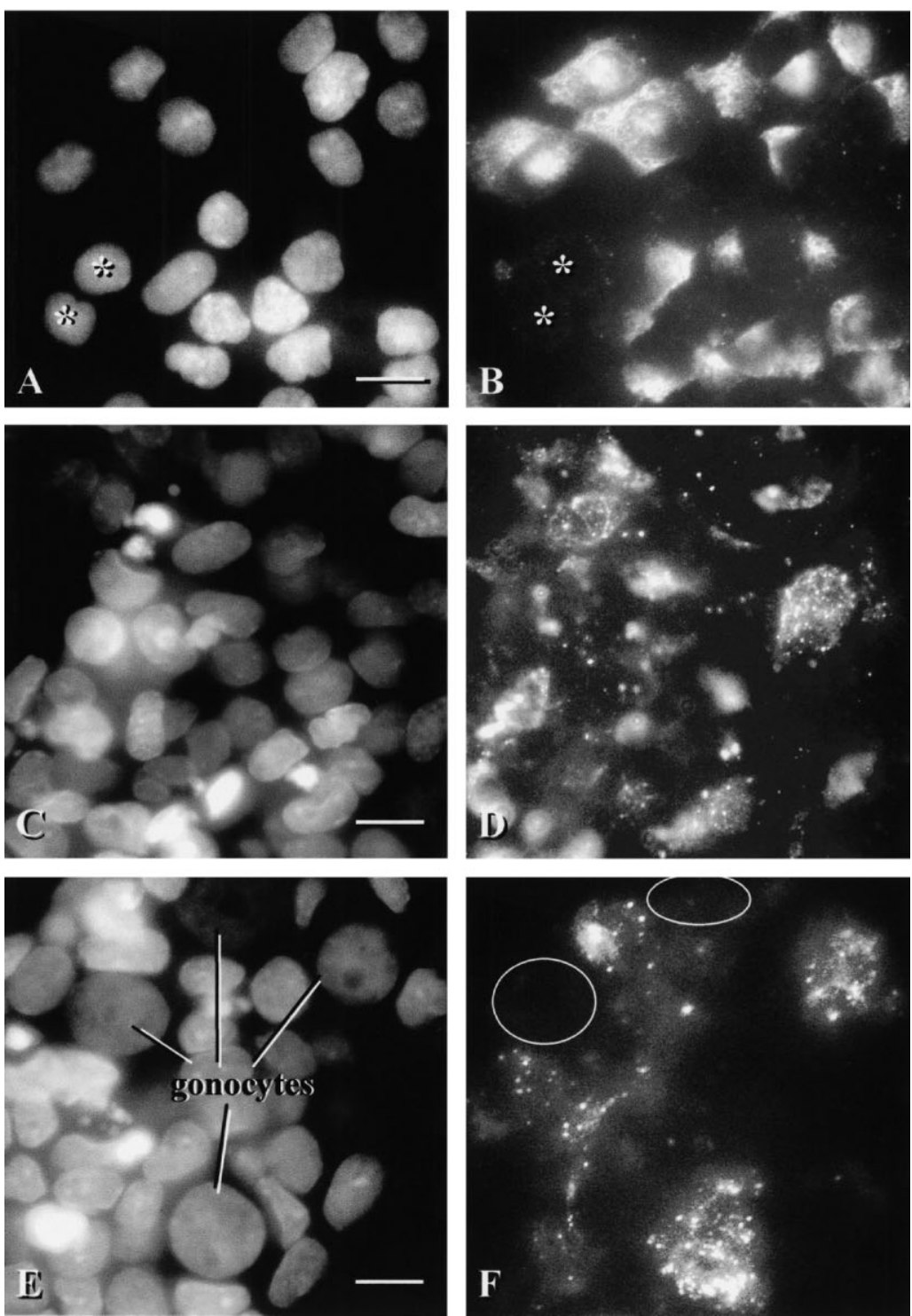
0.5 and $5.0 \mathrm{nM}$ of $\mathrm{T}_{3}$ compared with corresponding controls (Fig. 5). However, statistical analysis revealed no significant differences among these samples. An examination of STPB-C expression in cultures exposed to $\mathrm{T}_{3}$ $(1 \mathrm{nM})$ or vehicle for shorter $(6-12 \mathrm{~h})$ or longer $(36 \mathrm{~h})$ periods of incubation (Fig. 6) also revealed no significant effect of the hormone on STPB-C expression.

\section{Western analysis and immunolocalization of STPB-C protein}

An antiserum generated against a peptide sequence unique to STPB-C was used in Western analysis of protein samples obtained from testes of rats aged 1 or 5 days. The antiserum recognized a single prominent band of approximately $85 \mathrm{kDa}$ in immunoblots (Fig. 7A). Subsequently, the antiserum was used in immunofluorescent localizations of STPB-C in Sertoli cell-gonocyte co-cultures prepared on postnatal day 2 and analyzed after $24 \mathrm{~h}$ in culture. Figure 7B shows representative cultures stained either with DAPI (subpanels A, C and E) to visualize the cells present or with the STPB-C antiserum (subpanels B, D and F). Signal for STPB-C was strong in the great majority of Sertoli cells with only an occasional negative cell (Fig. 7B). In addition, when various planes of focus were examined in these cells, it was clear that fluorescent signal was both intracellular within the cell cytoplasm as well as localized to the surfaces of Sertoli cells (subpanel D). When gonocytes in these cultures were examined, many of these cells also displayed strong signal at cellular surfaces (subpanel F) as well as within the cells (not shown). However, in contrast to Sertoli cells many gonocytes were easily located which were totally lacking in signal. Two examples of negative gonocytes are identified in subpanel F. In additional cultures treated identically except for either omission of primary antiserum or substitution of pre-immune serum for the latter, no immunofluorescent signal was detected (not shown).

\section{Discussion}

Our finding of STPB-C expression in the developing rat testis in vivo and in vitro provides new evidence for a potential role of this adhesion factor in the testis.
Moreover, because Sertoli cell-gonocyte interactions play a crucial role in germ cell development, appropriate expression of STPB-C may be critical for normal onset of spermatogenesis and ultimate attainment of fertility in males. The final size of the gonocyte population is determined during the neonatal period of testicular maturation in vivo (Orth et al. 2000), when many of these germ cells undergo apoptosis (Knudson et al. 1995) while others survive. The postnatal wave of apoptosis and subsequent development of the surviving germ cells has been shown to be essential for normal quality and quantity of sperm production in adults (Knudson et al. 1995, Lee et al. 1997). Thus, surviving gonocytes which avoid apoptosis act as stem cells for all future generations of spermatogenic cells. In the light of the above information, it is clear that any factor which ensures continued attachment of maturing gonocytes to Sertoli cells will be important for further development of the spermatogenic population.

In previous studies from our laboratory, we documented that a non-cadherin, NCAM, is at least partly responsible for Sertoli cell-gonocyte adhesion in neonates (Laslett et al. 2000) and that its expression decreases substantially by day 15 and disappears in adults ( $\mathrm{Li}$ et al. 1998). We also found that $\mathrm{T}_{3}$ treatment of neonatal co-cultures results in downregulation of NCAM and, at higher concentrations or times of exposure, in detachment of approximately $80 \%$ of gonocytes from the underlying Sertoli cells (Laslett et al. 2000). Our current findings extend our understanding of the relationship between neonatal Sertoli and germ cells by identifying STPB-C as a potentially important factor expressed by both cell types at this time. Moreover, its pattern of expression in vivo differs from that of NCAM, with sustained levels of STPB-C expression between days 1 and 5 after birth, followed by a notable decline by day 10 to low levels sustained thereafter (Fig. 4). In our observations in in situ hybridizations and in immunolocalizations, most Sertoli cells in neonates expressed STPB-C while few if any were positive for STPB-C in adults. We also observed strong signal in some gonocytes while many others were negative. In post-pubertal testes, expression of STPB-C mRNA appeared to be restricted to the nuclei of primary spermatocytes. This pattern of expression suggests that STPB-C expression may be related, directly or indirectly, to differentiation of Sertoli cells which cease

\footnotetext{
Figure 7 (A) Western analysis of testicular protein samples obtained from 1- or 5-day-old pups (50 $\mu$ g/lane), probed with anti-STPB-C. The position of molecular mass markers is indicated to the right of the blot. (B) Immunofluorescent localization of STPB-C in Sertoli cell-gonocyte co-cultures prepared on postnatal day 2 and analyzed $24 \mathrm{~h}$ after plating. Images on the left show nuclear fluorescence for DAPI while those on the right show rhodamine fluorescence, indicating the presence of anti-STPB-C. Subpanels A and B: a view of Sertoli cells, with subpanel B showing an intracellular plane of focus at the level of the nuclei of most of the cells. Most Sertoli cells display strong intracellular signal for STPB-C, although an occasional cell lacking signal is present (two negative cells are indicated by asterisks). Subpanels C and D: a similar view of Sertoli cells as seen in subpanels A and B, with the plane of focus in subpanel D at the level of the cell surface. Note strong punctate fluorescence on the surfaces of several Sertoli cells. Subpanels E and F: a portion of a culture containing four gonocytes, easily recognizable by their large round nuclei and prominent nucleoli in subpanel E. Two of these cells display abundant punctate fluorescence at their surfaces in subpanel F, while two are totally negative. The location of these negative gonocytes has been indicated by white circles in subpanel F. Bar $=10 \mu \mathrm{m}$.
} 
mitotic activity at about 10 days of age (Orth 1982) and presumably all differentiate at that time or shortly thereafter. Currently available information identifies $\mathrm{T}_{3}$ as an important influence in Sertoli cell differentiation. For example, experimental hyperthyroidism leads to a shortened period of Sertoli cell proliferation and accelerated Sertoli cell differentiation, while hypothyroidism causes a prolonged period of Sertoli cell proliferation and a delay in differentiation of these cells (Van Haaster et al. 1993, Simorangkir et al. 1995, 1997). However, data presented here do not support a direct role for $\mathrm{T}_{3}$ in regulation of STPB-C expression. Further studies in this area should clarify the mechanism whereby the level of STPB-C is regulated as the testis matures and Sertoli cells differentiate.

Although evidence from the literature on the developing testis indicates that several other members of the cadherin family of adhesion factors are produced during testicular maturation, the patterns of their expression and their mechanism of action suggest that STPB-C may play a role distinct from that of these other cadherins. Johnson et al. (2000) explored expression of multiple cadherin superfamily members and reported that cadherins with the exception of $\mathrm{N}$-cadherin and cadherin-6 are expressed most abundantly around postnatal day 7 . In addition, for all members of the PCDH $\alpha$ family of cadherins, expression levels are generally high at day 7 and then remain at a steady-state from postnatal day 21 through adulthood (Johnson et al. 2000), a pattern different from that found for STPB-C. Moreover, a consideration of the molecular structure and subcellular interactions of STPB-C also supports the concept of a distinct role for this factor. Previously, both STPB-C and long-type PB-cadherin (LTPB-C) were found in pituitary and brain of rats (Sugimoto et al. 1996). However, unlike LTPB-C and the classic cadherins, STPB-C lacks a catenin-binding domain yet functions via an unknown, alternative mechanism in $\mathrm{Ca}^{+}$-dependent cell-cell interactions (Sugimoto et al. 1996). Thus, STPB-C induces functional changes in cells via $\mathrm{Ca}^{+}$-regulated actions that are distinct from those associated with the other cadherins.

In summary, we have detected expression of a novel factor, STPB-cadherin, by neonatal gonocytes and Sertoli cells and we have verified production of STPB-C protein in both cell types. Moreover, our observations suggest that this protein functions at cell surfaces to support contactmediated interactions which are important in survival of those gonocytes that are the foundation of all subsequent germ cell generations.

\section{Acknowledgement}

This work was supported by Grant HD-15563 (to J M O) from the National Institute of Child Health and Human Development.

\section{References}

Cook PS, Zhao YD \& Bunick D 1994 Triiodothyronine inhibits proliferation and stimulates differentiation of cultured neonatal Sertoli cells: possible mechanism for increased adult testis weight and sperm production induced by neonatal goitrogen treatment. Biology of Reproduction 51 1000-1005.

Francavilla S, Cordeschi G, Properzi G, Di Cicco L, Jannini EA, Palmero S, Fugassa E, Loras B \& D’Armiento M 1991 Effect of thyroid hormone on the pre- and postnatal development of the rat testis. Journal of Endocrinology 129 35-42.

Griswold M 1995 Interactions between germ cells and Sertoli cells in the testis. Biology of Reproduction 52 211-216.

Jannini EA, Ulisse S, Piersanti D, Carosa E, Muzi P, Lazar J \& D’Armiento M 1993 Early thyroid hormone treatment in rats increase testis size and germ cell number. Endocrinology 132 2726-2728.

Johnson KJ, Patel SR \& Boekelheide K 2000 Multiple cadherin superfamily members with unique expression profiles are produced in rat testis. Endocrinology 141 675-683.

Knudson CM, Tung KSK, Tourtellotte WG, Brown GAJ \& Korsmeyer SJ 1995 Bax-deficient mice with lymphoid hyperplasia and male germ cell death. Science 270 96-98.

Laslett AL, Li LH, Jester WF \& Orth JM 2000 Thyroid hormone down-regulates neural cell adhesion molecule expression and affects attachment of gonocytes in Sertoli cell-gonocyte cocultures. Endocrinology 141 1633-1641.

Lee J, Richburg JH, Younkin SC \& Boekelheide K 1997 The fas system is a key regulator of germ cell apoptosis in the testis. Endocrinology 138 2081-2088.

Li LH, Jester WF Jr \& Orth JM 1998 Expression of 140-kDa neural cell adhesion molecule in developing testes in vivo and in long-term Sertoli cell-gonocyte cocultures. Journal of Andrology 19 365-373.

Orth J 1982 Proliferation of Sertoli cells in fetal and postnatal rats: a quantitative autoradiographic study. Anatomical Record 203 485-492.

Orth JM \& Boehm R 1990 Functional coupling of neonatal rat Sertoli cells and gonocytes in coculture. Endocrinology 127 2812-2820.

Orth JM \& McGuinness MP 1991 Neonatal gonocytes cocultured with Sertoli cells on a laminin-containing matrix resume mitosis and elongate. Endocrinology 129 1119-1112.

Orth JM \& Jester WF Jr 1995 NCAM mediates adhesion between gonocytes and Sertoli cells in cocultures from testes of neonatal rats. Journal of Andrology 16 389-399.

Orth JM, Gunsalus GL \& Lamperti AA 1988 Evidence from Sertoli cell-depleted rats indicates that spermatid number in adults depends on numbers of Sertoli cells produced during perinatal development. Endocrinology 122 787-794.

Orth JM, Jester WF \& Qiu J 1996 Gonocytes in testes of neonatal rats express the c-kit gene. Molecular Reproduction and Development $\mathbf{4 5}$ 123-131.

Orth JM, Jester WF \& Laslett AL 2000 Gonocyte-Sertoli cell interactions during development of the neonatal rodent testis. Current Topics in Developmental Biology 50 103-124.

Palmero S, de Marchis M, Gallo G \& Fugassa E 1989 Thyroid hormone affects the development of Sertoli cell function in the rat. Journal of Endocrinology 123 105-111.

Palmero S, De Marco P \& Fugassa E 1995 Thyroid hormone receptor beta mRNA expression in Sertoli cells isolated from prepubertal testis. Journal of Molecular Endocrinology 14 131-134.

Simorangkir DR, de Kretser DM \& Wreford NG 1995 Increased numbers of Sertoli and germ cells in adult rat testes induced by synergistic action of transient neonatal hypothyroidism and neonatal hemicastration. Journal of Reproduction and Fertility 104 207-213.

Simorangkir DR, Wreford NG \& de Kretser DM 1997 Impaired germ cell development in the testes of immature rats with neonatal hypothyroidism. Journal of Andrology 18 186-193.

Sugimoto K, Honda S, Yamamoto T, Ueki T, Monden M, Kaji A, Matsumoto K \& Nakamura T 1996 Molecular cloning and 
characterization of a newly identified member of the cadherin family, PB-cadherin. Journal of Biological Chemistry 271 $11548-11556$.

Van Haaster LH, de Jong FH, Docter R \& de Rooij DG 1993 High neonatal triiodothyronine levels reduce the period of Sertoli cell proliferation and accelerate tubular lumen formation in the rat testis, and increase serum inhibin levels. Endocrinology 133 755-760.

Vleminckx K \& Kemler R 1999 Cadherins and tissue formation: integrating adhesion and signaling. Bioessays 21 211-220.
Weinbauer GF \& Wessels J 1999 Paracrine control of spermatogenesis. Andrologia 5 249-262.

Wright W 1993 Cellular interactions in the seminiferous epithelium. In Cell and Molecular Biology of the Testis, pp 377-399. Eds

C Desjardins \& L Ewing. New York: Oxford University Press.

Received in final form 28 October 2002

Accepted 7 November 2002 